\title{
NUMERICAL MODELING OF DIAGONAL CRACKS IN CONCRETE BEAMS
}

\author{
M. SŁOWIK ${ }^{1}$, P. SMARZEWSKI ${ }^{2}$
}

\begin{abstract}
In the paper, the method of a numerical simulation concerning diagonal crack propagation in concrete beams was presented. Two beams reinforced longitudinally but without shear reinforcement were considered during the Finite Element Method analysis. In particular, a nonlinear method was used to simulate the crack evaluation in the beams. The analysis was performed using the commercial program ANSYS. In the numerical simulation, the limit surface for concrete described by Willam and Warnke was applied to model the failure of concrete. To solve the FEM-system of equations, the Newton-Raphson method was used. As the results of FEM calculations, the trajectories of total stains and numerical images of smeared cracks were obtained for two analyzed beams: the slender beam S5 of $l_{\text {eff }}=1.8 \mathrm{~m}$ and the short beam S3k of $l_{\text {eff }}=1.1 \mathrm{~m}$. The applied method allowed to generate both flexural vertical cracks and diagonal cracks in the shear regions. Some differences in the evaluation of crack patterns in the beams were observed. The greater number of flexural vertical cracks which penetrated deeper in the beam S5 caused the lower stiffness and the greater deformation in the beam S5 compared to the short beam S3k. Numerical results were compared with the experimental data from the early tests performed by Słowik [3]. The numerical simulation yielded very similar results as the experiments and it confirmed that the character of failure process altered according to the effective length of the member. The proposed numerical procedure was successfully verified and it can be suitable for numerical analyses of diagonal crack propagation in concrete beams.
\end{abstract}

Key words: concrete beam, diagonal crack, numerical analysis

\section{INTRODUCTION}

Brittle failure takes place mostly in the materials in which stress relaxation cannot occur as a result of a dissipation process at the top of the crack. The most known brittle materials are ceramics, glass and hardened steel. Concrete is generally considered as quasi-brittle material because some plastic strains can develop during cracking. However, in some cases concrete behaves in a more brittle manner. Not only mechanical properties determine the mode of failure. In large scale concrete members, the development of plastic strain is limited and the fracture process has brittle character. Also

1 Lublin University of Technology, Faculty of Civil Engineering and Architecture, Nadbystrzycka 40, Lublin 20-618, Poland, e-mail: m.slowik@pollub.pl

2 Lublin University of Technology, e-mail: p.smarzewski@pollub.pl 
a decrease of temperature causes a decrease of plastic response and then concrete may work as a brittle material. These problems have been described for example by Brandt [1], Bažant and Planas [2].

The low tensile strength of concrete puts limits to the use of plain concrete in building structures. Therefore, concrete is usually reinforced and the general aim of reinforcement in members made of concrete is to carry tensile stress, to limit crack widths and to protect against brittle failure. Tensile strength is often disregarded in design for the Ultimate Limit State of reinforced concrete structures. But there are still a few design problems where tensile capacity is of paramount importance. One of them is so-called "shear failure" - a failure under combined shearing force and bending moment that takes place in flexural members. In longitudinally reinforced concrete beams without shear reinforcement, this type of failure reduces the strength and the ductility of the structural member.

The problem of shear failure in reinforced concrete beams without shear reinforcement was investigated experimentally and presented by Słowik [3]. It was found that the character of shear failure and diagonal crack propagation in the beams changed according to the shear span-to-depth ratio $a / d$ and the scale of the member. To analyze the influence of those parameters on failure process, numerical simulations were performed. A linear elastic analysis was applied (Słowik, Nowicki [4]) to investigate the influence of $a / d$ on diagonal crack propagation and a nonlinear analysis was carried out (Słowik, Smarzewski [5]), in which the changing parameter was the effective length of the beams.

It is a challenging task to model cracks in reinforced concrete members, especially when several cracks appear in the member. When modeling fracture mechanism, the nonlinear characteristic of concrete and reinforcing steel, in particular the softening of the materials, should be considered. Another complication arises at modeling the bond between concrete and steel. Furthermore, local large strain concentrations, which influence cracking and crushing in concrete, must be considered. To solve this complicated problem, a spatial model should be built, a three-dimensional stress-strain state should be considered and, last but not least, the proper method of solving the FEM-system of equations should be applied.

In the paper, the procedure of numerical modeling of diagonal cracks in longitudinally reinforced concrete beams is presented. This procedure has been applied in a numerical simulation in order to verify it. The comparison of the obtained numerical results with the test results is also discussed in the paper.

\section{Numerical Simulation}

In the performed numerical analysis, two beams corresponding to the tested members were modeled: one half of the beam S5 of $l_{\text {eff }}=1.8 \mathrm{~m}$ and the whole beam S3k of $l_{\text {eff }}=1.1 \mathrm{~m}$. The beams had the rectangular cross-section of the width $b=0.12 \mathrm{~m}$, the 
total depth $h=0.25 \mathrm{~m}$, and the effective depth $d=0.22 \mathrm{~m}$. The beam specimens were tested as simply supported beams under three-point bending. They were made from concrete of the compressive strength $f_{c}=32.7 \mathrm{MPa}$, the tensile strength $f_{c t}=3.0 \mathrm{MPa}$, the Young's modulus $E_{c}=37650 \mathrm{MPa}$. Two deformed steel bars with diameters of $18 \mathrm{~mm}$ were used as the bottom longitudinal reinforcement in the beams. The yield stress of the steel was $f_{y}=453 \mathrm{MPa}$ and the tensile strength was $f_{t}=698 \mathrm{MPa}$. More details of the performed experimental investigation can be found in [3].

The Finite Element Method calculations were performed using the ANSYS program. Eight-node solid elements were used to model the concrete. They were taken from the library of the ANSYS program. Every node of the solid element had three degrees of freedom - translation in the nodal $x, y$ and $z$ direction. The solid element was capable of describing plastic behavior, cracking and crushing of concrete in three axes of orthogonal system. Stress and strain components were calculated at integration points. The discrete model of reinforcement was applied. Reinforcing bars were modeled by three-dimensional bar elements. The connection between concrete and steel was established as identical displacement of connected nodes (see Figure 1).

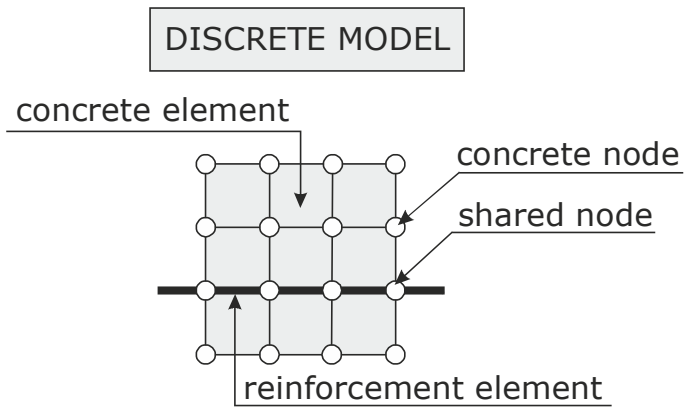

Fig. 1. Discrete model for reinforcement

A rectangular mesh was applied to model the beams. This kind of mesh is recommended when solid elements are used in numerical simulations. The FEM-meshes for both beams are presented in Figure 2 .
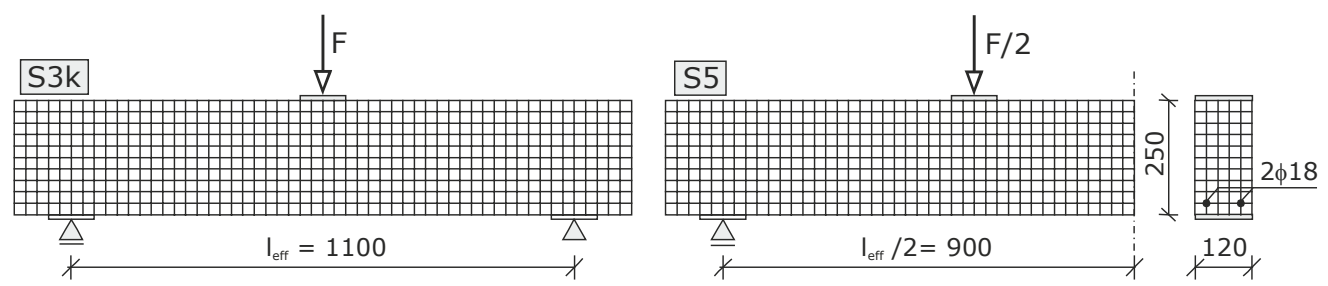

Fig. 2. FEM - mesh for beams S3k and S5 
The description of limit state of concrete under static and dynamic loading has been the subject of numerous papers. Limit surfaces for concrete were described for example by Willam and Warnke [6], Ottosen [7], Klisiński [8], Podgórski [9], Stolarski [10], Bobiński and Tejchman [11], Widuliński et al. [12], Jankowiak and Łodygowski [13]. In the paper, Willam and Warnke criterion described in [6] was chosen to model the failure of concrete. This criterion allows applying the nonlinear response of concrete for triaxial behavior. It is defined as:

$$
\frac{F}{f_{c}}-S \geq 0,
$$

where $F$ is the function of stress conditions $\sigma_{x p}, \sigma_{y p}, \sigma_{z p}$, in the direction of the Cartesian coordinate system $x, y, z ; S$ is the failure surface and $f_{c}$ is uniaxial compressive strength causing crushing. The failure surface depends on principal stresses $\sigma_{1}, \sigma_{2}, \sigma_{3}$, where: $\sigma_{1} \geq \sigma_{2} \geq \sigma_{3}, \sigma_{1}=\max \left(\sigma_{x p}, \sigma_{y p}, \sigma_{z p}\right), \sigma_{3}=\min \left(\sigma_{x p}, \sigma_{y p}, \sigma_{z p}\right)$, and on strength parameters: $f_{t}$ - uniaxial tension strength causing cracking; $f_{c b}$ - ultimate biaxial compressive strength causing crushing; $f_{1}$ - ultimate compressive strength for a state of biaxial compression superimposed on hydrostatic stress state $\sigma_{h}^{a} ; f_{2}$ - ultimate compressive strength for a state of uniaxial compression superimposed on hydrostatic stress state $\sigma_{h}^{a}$. The geometrical interpretation of the criteria is shown in Figure 3.



Fig. 3. The limit surface

The failure of concrete can be distinguished as the state of cracking when any principal stress is tensile or as the state of crushing when all principal stresses are compressive. 
In the state of compression - compression - compression, function $F$, corresponding to average tangential stress which is directly proportional to the second invariant of deviator, has the form:

$$
F=F_{1}=\frac{1}{\sqrt{15}}\left[\left(\sigma_{1}-\sigma_{2}\right)^{2}+\left(\sigma_{2}-\sigma_{3}\right)^{2}+\left(\sigma_{3}-\sigma_{1}\right)^{2}\right]^{\frac{1}{2}},
$$

and the elliptical failure surface $S$ is described on the basis of geometrical considerations in polar coordinates $r, \theta$ by the expression:

$$
S=S_{1}=\frac{2 r_{c}\left(r_{c}^{2}-r_{t}^{2}\right) \cos \theta+r_{c}\left(2 r_{t}-r_{c}\right)\left[4\left(r_{c}^{2}-r_{t}^{2}\right) \cos ^{2} \theta+5 r_{t}^{2}-4 r_{t} r_{c}\right]^{\frac{1}{2}}}{4\left(r_{c}^{2}-r_{t}^{2}\right) \cos ^{2} \theta+\left(r_{c}-2 r_{t}\right)^{2}}
$$

in which the angle $\theta$ corresponds to the third invariant of deviator; $r_{t}$ and $r_{c}$ are deviatoric sectional radii. Deviatoric sectional radius $r_{t}$ is determined by the parameters $a_{0}, a_{1}, a_{2}$ selected in such a way that $f_{t}, f_{c b}, f_{1}$ are located on the limit surface. The second deviatoric sectional radius $r_{c}$ is expressed by the parameters $b_{0}, b_{1}, b_{2}$ determined from the compression along the meridian for an angle $\theta=60^{\circ}$.

In the state of tension - compression - compression, function $F$ is written in the form:

$$
F=F_{2}=\frac{1}{\sqrt{15}}\left[\left(\sigma_{2}-\sigma_{3}\right)^{2}+\sigma_{2}^{2}+\sigma_{3}^{2}\right]^{\frac{1}{2}}
$$

and $S$ is defined by the equation:

$$
S=S_{2}=\left(1-\frac{\sigma_{1}}{f_{t}}\right) \frac{2 p_{c}\left(p_{c}^{2}-p_{t}^{2}\right) \cos \theta+p_{c}\left(2 p_{t}-p_{c}\right)\left[4\left(p_{c}^{2}-p_{t}^{2}\right) \cos ^{2} \theta+5 p_{t}^{2}-4 p_{t} p_{c}\right]^{\frac{1}{2}}}{4\left(p_{c}^{2}-p_{t}^{2}\right) \cos ^{2} \theta+\left(p_{c}-2 p_{t}\right)^{2}}
$$

In the Eq. (2.4), $p_{t}$ and $p_{c}$ are given by formulas:

$$
p_{t}=a_{0}+a_{1} \chi+a_{2} \chi^{2}, \quad p_{c}=b_{0}+b_{1} \chi+b_{2} \chi^{2} .
$$

in which $a_{0}, a_{1}, a_{2}$ and $b_{0}, b_{1}, b_{2}$ are defined as in the Eq. (2.2), whereas $\chi$ is 


$$
\chi=\frac{1}{3}\left(\sigma_{2}+\sigma_{3}\right)
$$

In the state of tension - tension - compression, functions $F$ and $S$ adopt the forms:

$$
F=F_{3}=\sigma_{i}, i=1,2, \quad S=S_{3}=\frac{f_{t}}{f_{c}}\left(1+\frac{\sigma_{3}}{f_{c}}\right) .
$$

In the state tension - tension - tension, functions $F$ and $S$ are defined as:

$$
F=F_{4}=\sigma_{i}, i=1,2,3, \quad S=S_{4}=\frac{f_{t}}{f_{c}} .
$$

More details about the limt surface of concrete were presented by Smarzewski in [14]. Uniaxial stress-strain relationships for concrete in compression and in tension, and for reinforcing steel in tension are presented in Figure 4.

Stress-strain characteristic for concrete in compression $\sigma_{c}-\varepsilon_{c}$ was adopted in numerical simulation on the basis of the Desayi and Krishnan proposition presented in [15]:

$$
\sigma_{c}=\frac{E_{c} \varepsilon_{c}}{1+\left(\frac{\varepsilon_{c}}{\varepsilon_{c 1}}\right)^{2}}, \quad \varepsilon_{c 1}=\frac{2 f_{c}}{E_{c}},
$$

where: $\varepsilon_{c 1}$ is the strain corresponding to the limit compressive strength $f_{c}$ and $E_{c}$ is the modulus of elasticity for concrete.

In Figure 4a, the strain in point 1 indicates the end of the region of non-cracked concrete elasticity. After reaching point 4, perfectly-plastic behavior of concrete is assumed. In the description of tensile concrete (Figure $4 \mathrm{~b}$ ), the stiffness multiplier for cracked tensile condition, $T_{c}=0.6$, is used to include tensile stress relaxation after cracking. The softening effect of tensile concrete is considered by using the declining stress curve characterized by $R_{t}$. The steel is assumed to be a multilinear isotropic hardening material as presented in Figure 4c. 

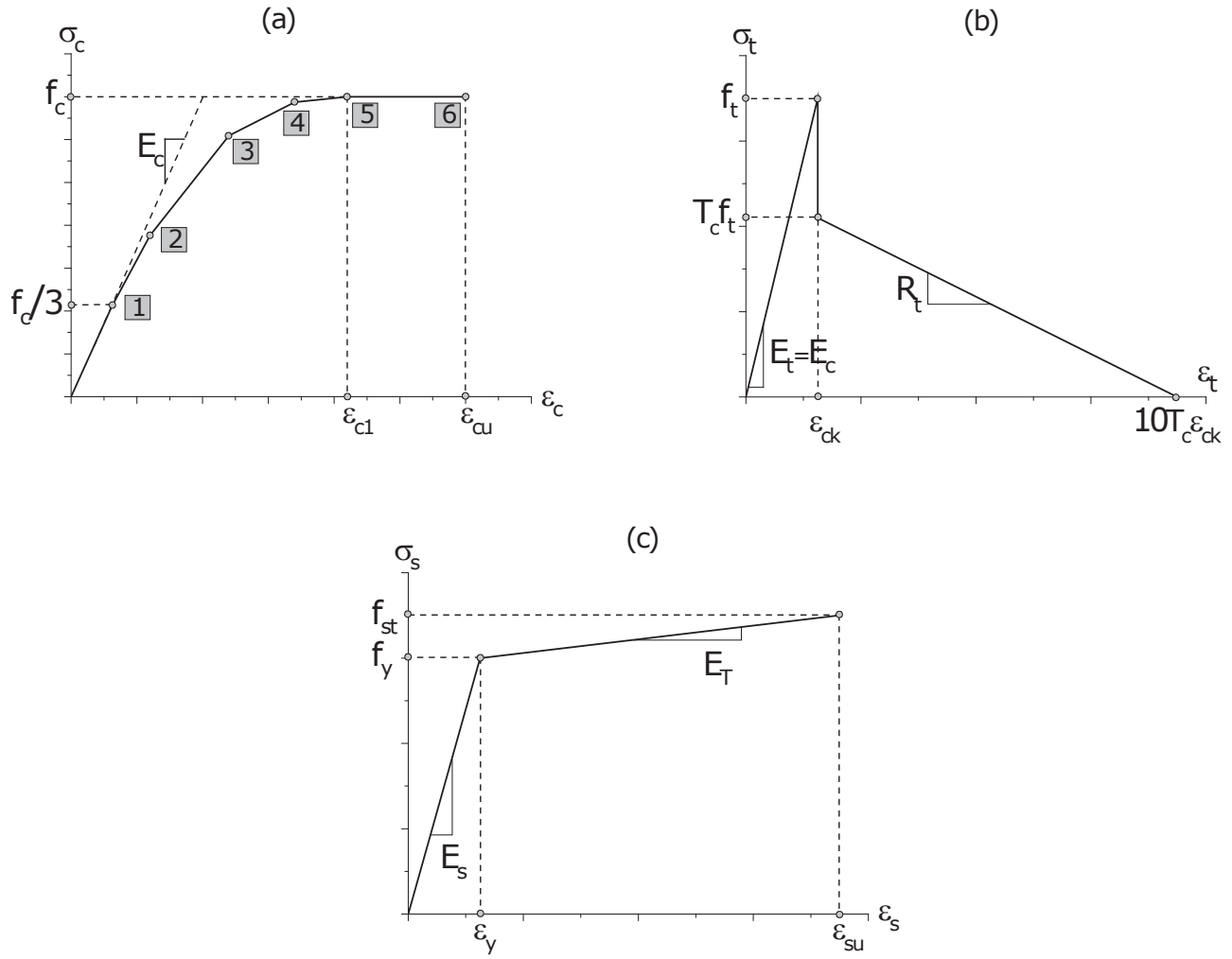

Fig. 4. Stress-strain relationships for materials: a) concrete in compression, b) concrete in tension, c) steel reinforcement in tension

In FEM-calculations, cracking occurred in the concrete element when tensile stress in any direction laid outside the failure surface, and then elastic modulus in the direction parallel to the principal tensile stress direction fell down to zero. Crushing occurred when three principal compressive stress components were outside the failure surface and then the element effectively disappeared. A cracking sign was represented by a circle (as shown in Figure 5) and it appeared at the integration point when principal tensile stress reached the ultimate concrete tensile strength. If any crack opened and closed, it was shown as a circle with a cross inscribed in the graphical representation of the crack. Cracks at any point of numerical integration were marked as the circles of different colours: red for the first crack, green for the second crack, blue for the third crack. Crushing of the material was presented as the octahedron. The sign described in the middle element showed the actual status of the destruction of the material in the finite element. For the numerical balance in the finite element in the state of concrete cracking or crushing, a small value of stiffness was added. 




Fig. 5. Cracking outline

The matrix of elasticity for an isotropic material $\mathbf{D}_{\mathbf{c}}$ is represented in the form:

$$
\mathbf{D}_{\mathbf{c}}=\frac{E_{c}}{\left(1+v_{c}\right)\left(1-2 v_{c}\right)}\left[\begin{array}{cccccc}
1-v_{c} & v_{c} & v_{c} & 0 & 0 & 0 \\
v_{c} & 1-v_{c} & v_{c} & 0 & 0 & 0 \\
v_{c} & v_{c} & 1-v_{c} & 0 & 0 & 0 \\
0 & 0 & 0 & \frac{1-2 v_{c}}{2} & 0 & 0 \\
0 & 0 & 0 & 0 & \frac{1-2 v_{c}}{2} & 0 \\
0 & 0 & 0 & 0 & 0 & \frac{1-2 v_{c}}{2}
\end{array}\right] \text {, }
$$

where $v_{c}$ is the Poisson's ratio.

The creation of a crack at the point of numerical integration was described by modified stiffness matrix in which the weakened plane located perpendicular to the cracking surface was incorporated. The parameter $\beta_{t}$ is a multiplier used for reducing shear transfer causing slip in the plane perpendicular to the surface cracks. The relationship between stress and strain of the material cracked in one plane is written in the form of a matrix: 


$$
\mathbf{D}_{\mathbf{c}}^{\mathbf{c k}}=\frac{E_{c}}{1+v_{c}}\left[\begin{array}{cccccc}
\frac{R_{t}\left(1+v_{c}\right)}{E_{c}} & 0 & 0 & 0 & 0 & 0 \\
0 & \frac{1}{1-v_{c}} & \frac{v_{c}}{1-v_{c}} & 0 & 0 & 0 \\
0 & \frac{v_{c}}{1-v_{c}} & \frac{1}{1-v_{c}} & 0 & 0 & 0 \\
0 & 0 & 0 & \frac{\beta_{t}}{2} & 0 & 0 \\
0 & 0 & 0 & 0 & \frac{1}{2} & 0 \\
0 & 0 & 0 & 0 & 0 & \frac{\beta_{t}}{2}
\end{array}\right] .
$$

All the compressive normal stresses in the cracked plane are transferred across the crack during its closing. In the matrix $\mathbf{D}_{\mathbf{c}}^{\mathbf{c k}}$ shear parameter $\beta_{c}$ is introduced, when the cracks close:

$(2.9) \mathbf{D}_{\mathbf{c}}^{\mathbf{c k}}=\frac{E_{c}}{\left(1+v_{c}\right)\left(1-2 v_{c}\right)}\left[\begin{array}{cccccc}1-v_{c} & v_{c} & v_{c} & 0 & 0 & 0 \\ v_{c} & 1-v_{c} & v_{c} & 0 & 0 & 0 \\ v_{c} & v_{c} & 1-v_{c} & 0 & 0 & 0 \\ 0 & 0 & 0 & \frac{\beta_{c}\left(1-2 v_{c}\right)}{2} & 0 & 0 \\ 0 & 0 & 0 & 0 & \frac{1-2 v_{c}}{2} & 0 \\ 0 & 0 & 0 & 0 & 0 & \frac{\beta_{c}\left(1-2 v_{c}\right)}{2}\end{array}\right]$.

Stiffness matrix for concrete cracked in two and three dimensions is of the form: 
$(2.10)$

$$
\mathbf{D}_{\mathbf{c}}^{\text {ck }}=E_{c}\left[\begin{array}{cccccc}
\frac{R_{t}}{E_{c}} & 0 & 0 & 0 & 0 & 0 \\
0 & \frac{R_{t}}{E_{c}} & 0 & 0 & 0 & 0 \\
0 & 0 & 1 & 0 & 0 & 0 \\
0 & 0 & 0 & \frac{\beta_{t}}{2\left(1+v_{c}\right)} & 0 & 0 \\
0 & 0 & 0 & 0 & \frac{\beta_{t}}{2\left(1+v_{c}\right)} & 0 \\
0 & 0 & 0 & 0 & 0 & \frac{\beta_{t}}{2\left(1+v_{c}\right)}
\end{array}\right] .
$$

When the cracks close in two or three planes, the relationship is expressed in a matrix form Eq. (2.9). The relationship between stress and strain for concrete cracked in three dimensions is written as a matrix Eq. (2.10).

The matrix element $\mathbf{D}_{\mathbf{c}}^{\mathbf{c k}}$ is used to transform the local coordinate system to the global one:

$$
\mathbf{D}_{\mathbf{c}}=\mathbf{T}^{\mathbf{c k}} \mathbf{T}^{\mathrm{ck}} \mathbf{D}_{\mathbf{c}}^{\mathbf{c k}},
$$

where $\mathbf{T}^{\mathbf{k}}$ is the transformation described by Suidan and Schnobrich [16].

Opening or closing of cracks at the point of numerical integration depends on the sign of the cracking strain. A crack is closed when the value of the cracking strain $\varepsilon_{c k}^{c k}$ is less than zero, and it is opened in the opposite case. The shear transfer coefficient $\beta_{t}=0,5$ is used to represent shear strength reduction for the load of a sliding development and the shear transfer coefficient $\beta_{c}=0,9$ is used to initiate crack's closing. Concrete crushing at the point of numerical integration occurs when it is destructive upon uniaxial, biaxial and triaxial compression. Crushing in the finite element is described on the basis of the plastic flow theory. In the area of crushed material, a further load increase causes strain growth at the constant residual stress.

To solve the FEM-system of equations, the Newton-Raphson method was applied, as described by Bathe [17], Zienkiewicz and Taylor [18], Bonet and Wood [19], Crisfield [20]. After meshing into finite elements, the following system of algebraic equations was created:

$$
\mathbf{K u}=\mathbf{F}^{a},
$$


in which $\mathbf{K}$ is the coefficient matrix; $\mathbf{u}$ is the generalized displacement vector in three orthogonal directions; $\mathbf{F}^{a}$ is the generalized load vector.

Newton-Raphson method represents an iterative process of solving nonlinear equations:

$$
\mathbf{K}_{i}^{T} \Delta \mathbf{u}_{i}=\mathbf{F}^{a}-\mathbf{F}_{i}^{n r},
$$

$$
\mathbf{u}_{i+1}=\mathbf{u}_{i}+\Delta \mathbf{u}_{i},
$$

where: $\mathbf{K}_{i}^{T}$ is the tangent stiffness matrix; index $i$ corresponds to the number of the incremental step; $\mathbf{F}_{i}^{n r}$ is the vector of restoring loads representing the element internal loads in the discretized system. The method is shown graphically in Figure 6:

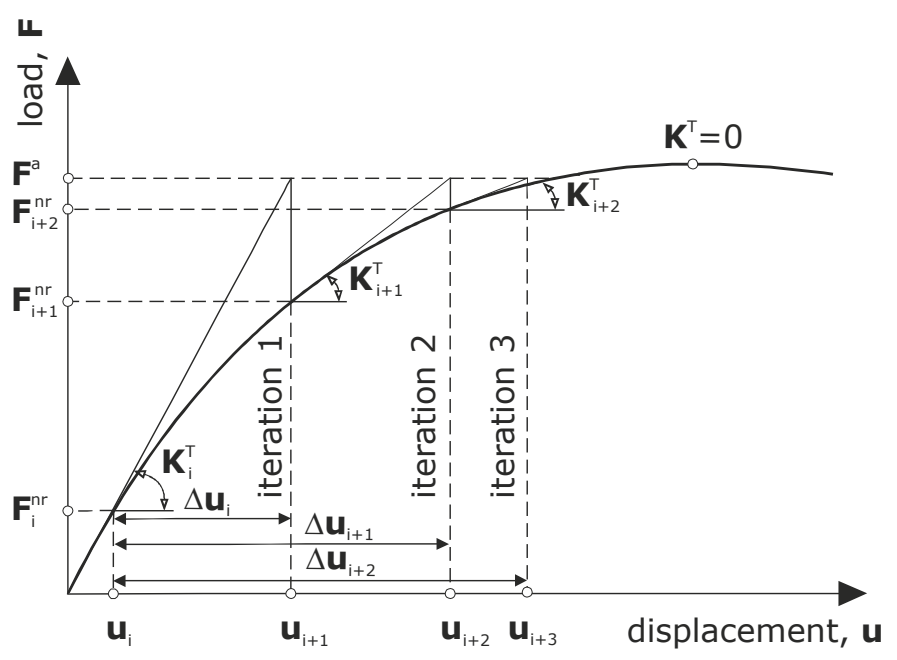

Fig. 6. Newton-Raphson method

Matrix $\mathbf{K}_{i}^{T}$ and vector $\mathbf{F}_{i}^{n r}$ are calculated on the basis of the displacement vector $\mathbf{u}_{i}$. The right side of Eq. (2.11) is called the unbalanced load vector. The solution is converged as a result of at least one iteration, when the vector of internal nodal forces $\mathbf{F}_{i}^{n r}$ at the current state of stress is equal to a generalized load vector $\mathbf{F}^{a}$ or a tolerance of solution is maintained.

\section{Results and Discussion}

As a result of FEM calculations, the dislocations of nodes and stress components along three axes of the global coordinate system were obtained. On the basis of the 
numerical results, trajectories of total strains were generated by ANSYS program. The trajectories for both beams, the beam S3k of $l_{\text {eff }}=1.1 \mathrm{~m}$ and the $\mathrm{S} 5$ of $l_{\text {eff }}=1.8 \mathrm{~m}$, in the subsequent load stages are presented in Figure 7. The trajectories indicated also the view of principal stress streams in the analyzed beams. When comparing strain distribution in the short beam and in the longer beam we can observe some differences in the damage process depending on the beam's length. These differences can be noticed when the evaluations of crack patterns are juxtaposed (see Figure 8). Here we can analyze very precisely the process of cracks evaluation. The first cracks occurred in the middle of the beam span and they propagated in the vertical direction. When the load reached approximately $40 \mathrm{kN}$ the shear stress made some flexural cracks in the shear regions change their orientation and become diagonal cracks. With the further load increase, the compressive cracks appeared in the region where the load was applied. A similar cracks evaluation was observed during the test.
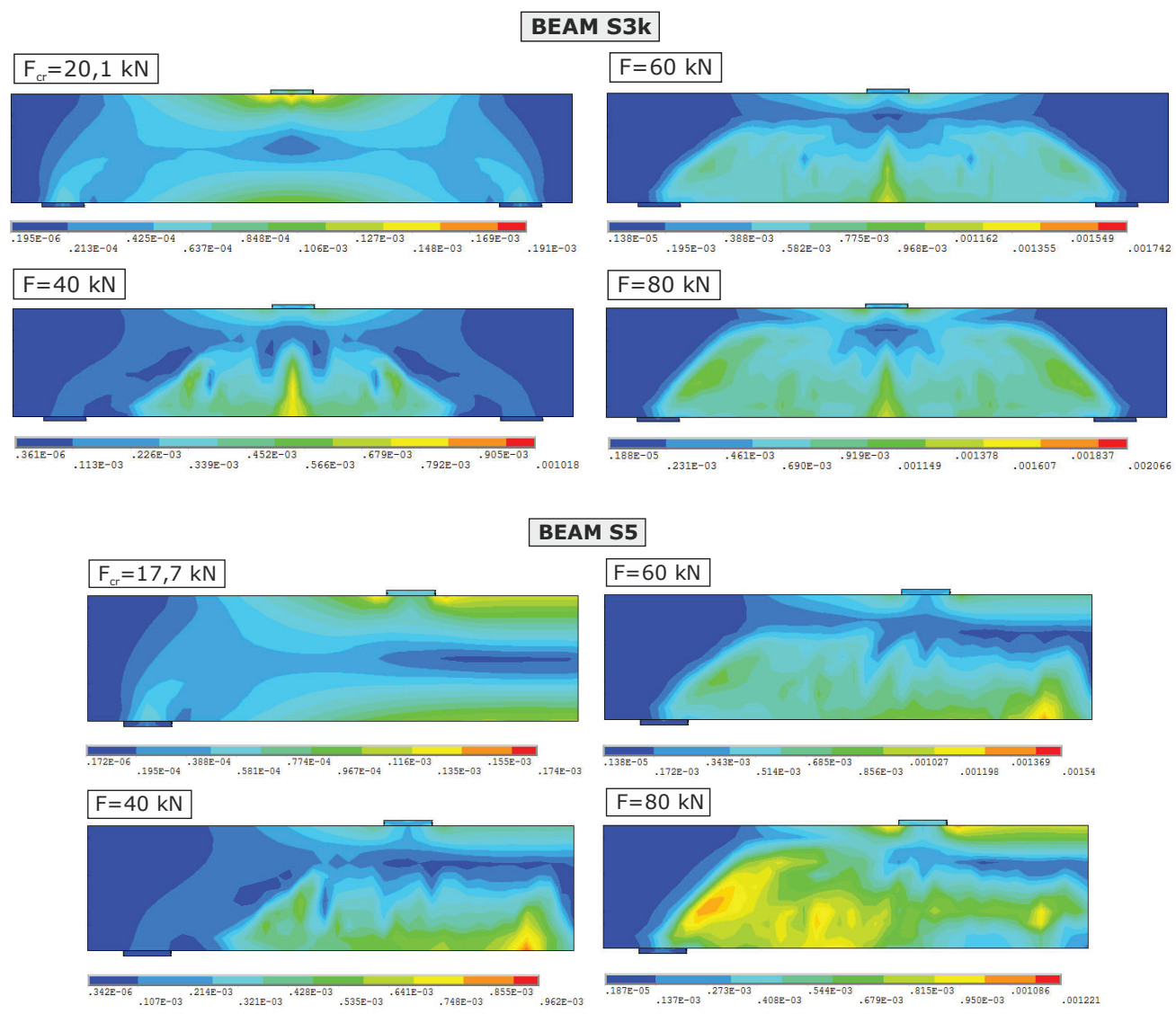

Fig. 7. Strain trajectories for beams S3k and S5 at different load levels 

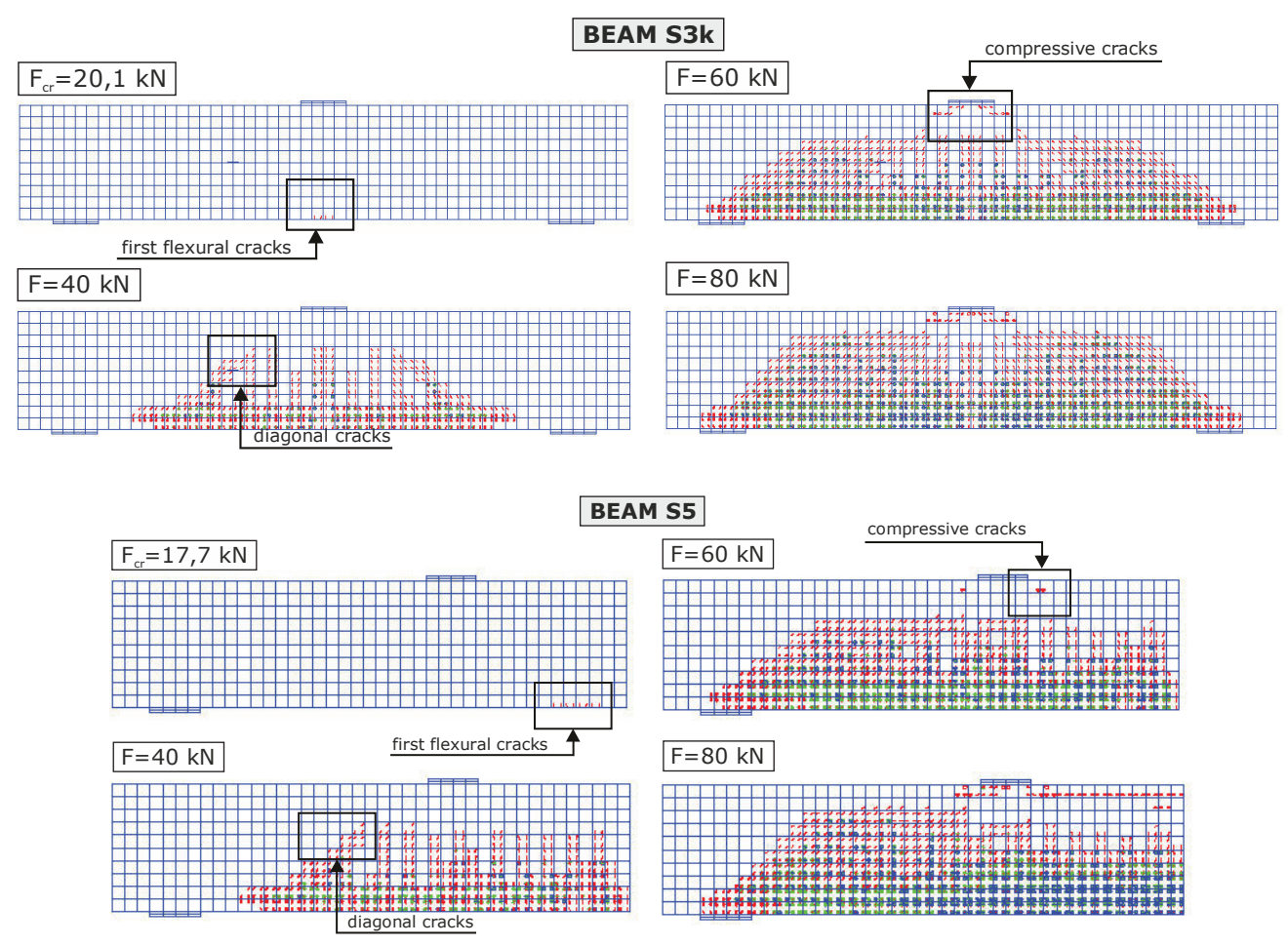

Fig. 8. Evolution of crack patterns for beams S3k and S5

According to the obtained strain distributions, the following zones of stress state can be distinguished in the beams: bending zone in the mid span; shear-bending zone in the region of diagonal cracks; shear-compression zone in the upper part of the beam near the applied forces. The intensity of strain in the following zones indicated what kind of damage process predominated in the beams. The increase of strains in the shear-bending zone was more intensive in the beam S5, which marked sudden failure. A similar observation was made during the experiment where the failure had more brittle character in the longer beam.

A good agreement is also seen when comparing the numerical images of smeared cracks and the strain distribution with the final crack patterns observed during the experiment under ultimate load (see Figure 9). It can be concluded that the numerical model, which was used in the numerical simulation, can be applied for the analysis of diagonal cracks in reinforced concrete members.

It was observed that the FEM-calculations were in good agreement with the experimental results for both analyzed beams. In the numerical simulation, a lower deflection in the middle of the beam was obtained in the beam S5 compared to the short beam 
S3k. This fact can be explained by the lower stiffness in the beam S5 due to the greater number of flexural vertical cracks which penetrated deeper in the beam S5 compared to the short beam S3k. The numerical simulation yielded very similar results as the experiments and it confirmed that the character of failure process altered according to the effective length of the member.

\section{BEAM S3k $F_{u}=102 \mathrm{kN}$}
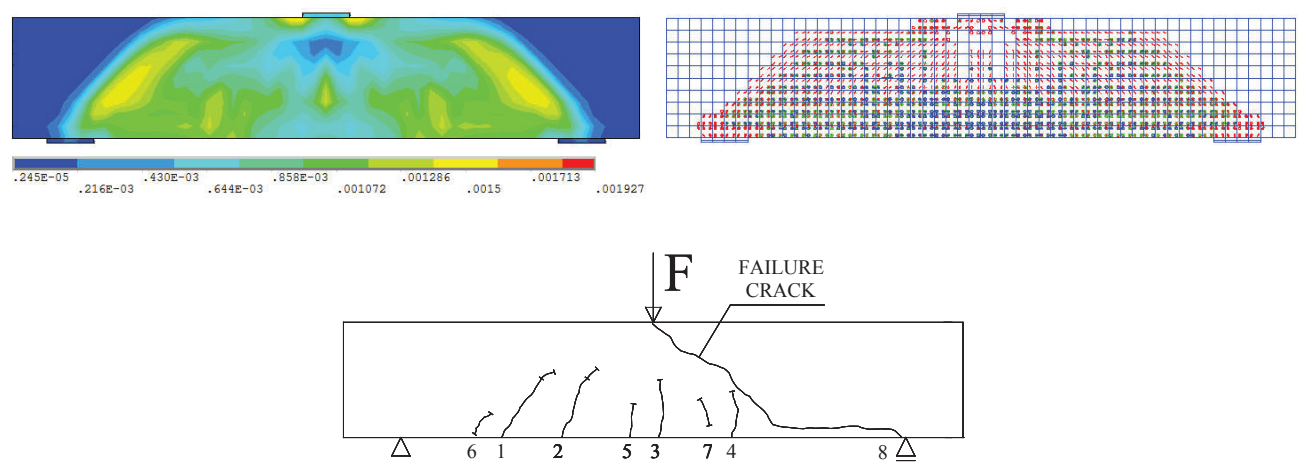

\section{BEAM S5 $\mathrm{F}_{\mathrm{u}}=81 \mathrm{kN}$}
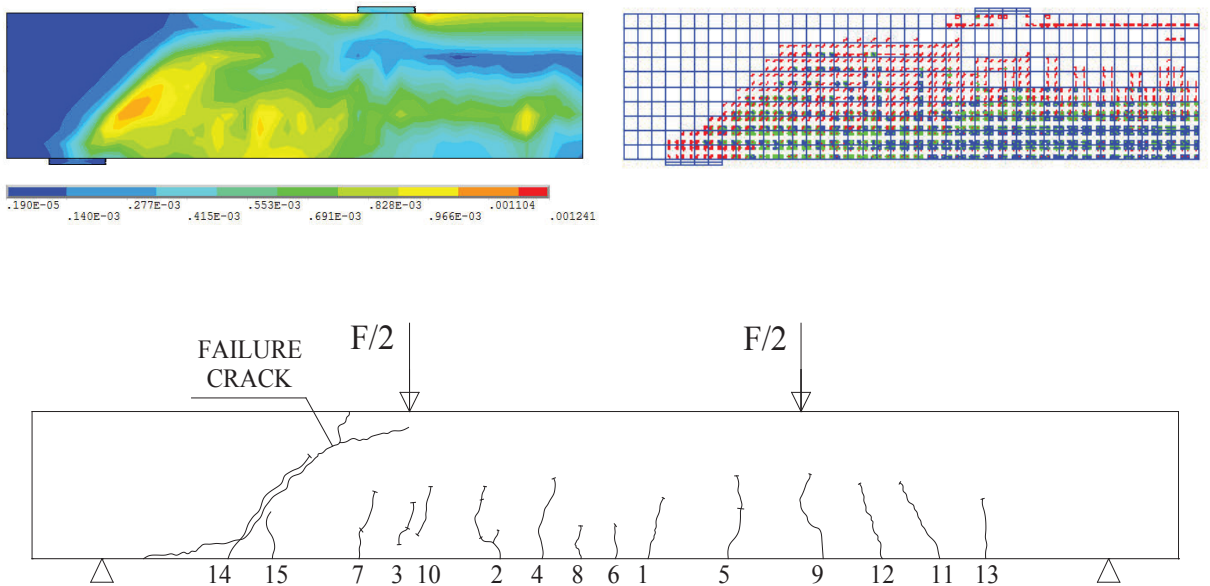

$\mathrm{F} / 2$

125

550

700

550 125

Fig. 9. Cracks pattern - comparison of numerical and experimental results 


\section{Conclusions}

In this paper, the procedure for numerical modeling of diagonal cracks in concrete beams has been presented. The numerical results obtained for two beams of different $l_{\text {eff }}$ were successfully confronted with the experimental results. The strain trajectories describe accurately the crack development in the beams. It can be concluded that the numerical model, which was used in numerical simulation, can be applied for analysis of diagonal cracks in reinforced concrete members.

Although the applied model gives realistic results, the authors plan to improve the numerical simulation. It has been noticed that the Newton-Raphson method, which was used in the performed numerical analysis, has some disadvantages. It is not adequate for materials of higher nonlinear characteristic. The experimental investigation performed by Ashour [21], Rashid and Mansur [22], showed that stress in the tension zone after cracking was not compensated by elastic steel response and plastic concrete response in compression zone, and therefore some softening effects were observed on load-deflection curve as a rapid decrease of load. In numerical simulations those effects can be obtained by using an arc-length algorithm described by Riks [23] and Crisfield [24]. This algorithm allows generating a complete path of solution with local stiffness decrease and global softening.

Further research should be encouraged to analyze the diagonal crack propagation process in longitudinally reinforced concrete members. It is planned to use the arclength method described by Crisfield [24] in combination with the Newton-Raphson method, to trace the complete response in load-deformation space. It seems that this modified method can be effectively applied to the static deformation mechanism analysis of various reinforced concrete members under complex stress states.

\section{REFERENCES}

1. A. M. Brandt, Cement Based Composites. Materials, Mechanical Properties and Performance, $2^{\text {nd }}$ edition, Taylor \& Francis, London and New York, 2009.

2. Z. P. Bažant, J. Planas, Fracture and Size Effect in Concrete and Quasibrittle Materials, CRC Press LLC, Boca Raton, 1998.

3. M. SŁowıк, Experimental study of shear failure mechanism in concrete beams, Brittle Matrix Composites 10, IFTR and Woodhead Publishing Limited, Warsaw, 345-354, 2012 (proceeding of the Tenth International Symposium on Brittle Matrix Composites).

4. M. SŁowiк, T. Nowicki, The Analysis of Diagonal Crack Propagation in Concrete Beams, Computational Materials Science, 52, 261-7, 2012.

5. M. SŁowik, P. Smarzewski, The Study of the Scale Effect on Diagonal Crack Propagation in Concrete Beams, Computational Materials Science, 64, 216-20, 2012.

6. K. J. Willam, E. P. Warnke, Constitutive Model for the Triaxial Behavior of Concrete, proceedings, International Association for Bridge and Structural Engineering, Vol. 19, ISMES, Bergamo, Italy, 1-30, 1975. 
7. N. S. Ottosen, A Failure Criterion for Concrete, Journal of the Engineering Mechanics Division, American Society of Civil Engineering, 103 (EM 4), 527-535, 1977.

8. M. Klisiśski, Degradation and plastic deformation of concrete (in Polish), Institute of Fundamental Technological Research Polish Academy of Sciences Report 38, Warsaw, 1984.

9. J. Podgórski, Critical States in Solids with Internal Friction (in Polish), Institute of Fundamental Technological Research Polish Academy of Sciences Report 25, Warsaw, 1986.

10. A. Stolarski, Dynamic Strength Criterion for Concrete, Journal of Engineering Mechanics, ASCE, 130, 1428-1435, 2004.

11. J. Bobiński, J. Tejchman, Modelling of size effects in concrete using elasto-plasticity with non-local softening, Archives of Civil Engineering, 52, 1, 7-35, 2006.

12. Ł. Widuliński, J. Bobiński, J. Tejchman, FE-analysis of spacing of localized zones in reinforced concrete bars under tension using elasto-plasticity with non-local softening, Archives of Civil Engineering, LV, 2, 257-281, 2009.

13. T. Jankowiak, T. Łodygowski, Quasi-static failure criteria for concrete, Archives of Civil Engineering, LVI, 2, 123-154, 2010.

14. P. Smarzewski, Modeling of Static Behavior of Inelastic Reinforced High-Strength Concrete Beams (in Polish), Monographs - Lublin University of Technology, 2011.

15. P. Desayi,, S. Krishnan, Equation for the Stress-Strain Curve of Concrete, Journal of the American Concrete Institute, 61, 345-350, 1964.

16. M. Suidan, W. C. Schnobrich, Finite Element Analysis of Reinforced Concrete, Journal of the Structural Division, ASCE, ST10, 2109-2122, 1973.

17. K. J. Bathe, Finite Element Procedures, Prentice-Hall, Inc., Upper Saddle River, New Jersey, 1996.

18. O. C. Zienkiewicz, R. L. Taylor, The Finite Element Method for Solid and Structural Mechanics, $6^{\text {th }}$ edition, Elsevier Butterworth Heinemann, Oxford, UK, 2005.

19. J. Bonet, R. D. Wood, Nonlinear Continuum Mechanics for Finite Element Analysis, Cambridge University Press, Cambridge, UK, 1997.

20. M. A. Crisfield, Non-Linear Finite Element Analysis of Solids and Structures, John Wiley \& Sons, Inc., Chichester, UK, 2000.

21. S. A. Ashour, Effect of Compressive Strength and Tensile Reinforcement Ratio on Flexural Behaviour of High-Strength Concrete Beams, Engineering Structures, 22, 413-423, 2000.

22. M. A. Rashid, M. A. Mansur, Reinforced High-Strength Concrete Beams in Flexure, ACI Structural Journal, 102, 462-471, 2005.

23. E. Riks, An Incremental Approach to the Solution of Snapping and Buckling Problems, International Journal of Solids and Structures, 15, 529-551, 1979.

24. M. A. Crisfield, An Arc-Length Method Including Line Searches and Accelerations, International Journal for Numerical Methods in Engineering, 19, 1269-1289, 1983. 